Moreno Albors, Marc.

Doctorando, Universitat Politècnica de València.

Grupo de investigación "Recuperación de prácticas pioneras del arte de acción de la vanguardia

histórica española y su contribución a la historia de la performance europea" (HAR2014-58869-P).

\title{
Uso de nuevas grafías musicales por parte de los compositores actuales: la obra Skin's Traces como ejemplo de integración y de notación no convencional.
}

\section{Use of new musical graphics by current composers: the work Skin's Traces as an example of integration and non- conventional notation.}

TIPO DE TRABAJO:

Comunicación.

PALABRAS CLAVE:

Tesis doctoral, notación musical, interpretación musical, multipercusión , arte sonoro.

KEY WORDS:

Phd thesis, musical notation, musical performance, multi-percussion, sound art.

RESUMEN.

Uno de los capítulos más importantes de mi tesis doctoral "La multipercusión en España desde el ámbito musical al arte sonoro. Evolución histórica y su aplicación práctica interpretativa-performativa" (actualmente en proceso por la Universitat Politècnica de València), es el dedicado a la aparición y desarrollo de nuevos recursos de notación musical. Históricamente la partitura ha servido de medio de transmisión entre las ideas del compositor y el intérprete, pero éstas han sufrido un largo camino de evolución otorgando a la partitura un valor plástico que va más allá de su funcionalidad puramente práctica. En el siglo XX la música y las artes plásticas convergen: los artistas visuales trabajan con el sonido de igual manera que los músicos introducen recursos visuales en sus obras. Ejemplo del uso del dibujo, la mancha y la línea como instrumento de representación sonora es la obra Skin's Traces (2006) del compositor Juanjo Eslava (Gijón,1970). En esta composición para frame-drum y electrónica, el intérprete deberá extraer las ideas sonoras dibujadas y transformar las grafías lineales en sonidos utilizando la percusión. Mi tesis doctoral utiliza una metodología basada en la investigación desde la práctica. Por lo tanto, mostraré ejemplos de integración de teoría y práctica dentro de la interpretación musical, ofreciendo en vivo para esta comunicación, algunas pautas para reproducir los sonidos trazados por estas grafías.

\section{ABSTRACT.}

One of the most important chapters of my doctoral thesis "Multi-percussion in Spain from the musical field to the sound art. Historical evolution and its practical interpretive-performative application" (nowadays in process by the Universitat Politècnica de València), is the one regarding the emergence and development of new musical notation resources. Historically the score has been used as a means of transmission between the ideas of the composer and the interpreter. But these have gone a long way in evolving, which gives the score a plastic value that goes beyond its purely practical functionality. In the 
twentieth century music and visual arts converge: visual artists work with sound just as musicians introduce visual resources into their works.

An example of the use of the drawing, the spot and the line as an instrument of sound representation is the work Skin's Traces (2006) by the composer Juanjo Eslava (Gijon, 1970).

In this composition for frame-drum and electronics, the interpreter will have to decipher the code that represents the sonorous drawn idea and turn the linear graphics into sounds using the percussion.

My doctoral thesis uses a methodology based on "practices-based research". Therefore, I will show examples of integration of theory and practice within the musical interpretation, live offering for this communication some guidelines to reproduce the sounds drawn by these graphics.

\section{CONTENIDO.}

\section{INTRODUCCIÓN.}

Dentro de los contenidos que forman parte de mi investigación doctoral, dirigí mi interés hacia la música experimental y su relación con el arte sonoro tomando como punto de partida la música para instrumentos de percusión.

Uno de los puntos más importantes de esta investigación doctoral será el relacionado con la interpretación de las nuevas formas de grafías musicales, siguiendo el ejemplo de la obra del compositor Juan José Eslava Skin's Traces (2006).

Para poder interpretar esta obra es necesario descifrar anteriormente una serie de dibujos y signos que nos propone el compositor. Esta escritura gráfica representa una novedad respecto a la escritura musical tradicional, por lo que consideramos necesario metodológicamente plantear sus orígenes y encontrar distintas formas de interpretación que explorasen la máxima fidelidad a la partitura con el objetivo de conseguir una mejor percepción por parte del oyente.

A partir de la investigación de la evolución de las nuevas grafías musicales encontraremos distintas soluciones por parte de los compositores del siglo XX para representar de una manera más adecuada las nuevas sonoridades con las que estaban trabajando. Más específicamente, descubriremos la diversa procedencia de los componentes que forman la obra Skin's Traces, lo cual nos mostrará como los compositores actuales trabajan inspirándose en distintas fuentes culturales a la hora de realizar sus piezas musicales.

La comunicación que presentaremos trata de enseñar cómo, investigando sobre las bases de las nuevas grafías que trajeron conjuntamente la evolución de la música experimental y el arte sonoro, se consigue la interpretación de una partitura cuyos códigos no representan la tradición musical aprendida académicamente. Añadimos también mi ejecución práctica interpretativa, como parte de la investigación.

La partitura es el objeto en el que habitualmente se representa el sonido para su interpretación. Sin embargo, la notación escrita ha sufrido un largo camino evolutivo debido principalmente a la aparición de nuevas formas de producir el sonido que obligaron paralelamente a buscar otras formas de relacionar la música que no estuvieran basadas en los principios históricos de la notación musical. La relación entre los sonidos y su imagen y plasticidad ha sido motivo de reflexión a lo largo de la historia desde la escuela acusmática pitagórica, pasando por los neumas medievales hasta la actualidad.

La liberación de la grafía musical tendrá su máxima representación en los principales músicos experimentales y de la vanguardia del siglo XX. El compositor Cornelius Cardew resumirá esta explosión de ideas creativas para la notación: “Un compositor que oye sonidos intentará encontrar una notación para los sonidos. Uno que tenga ideas encontrará una notación para sus ideas"1.

\footnotetext{
${ }^{1}$ Nyman, M.: Música experimental. De John Cage en adelante. Girona: Documentia Universitari, 2006, p.25.
} 


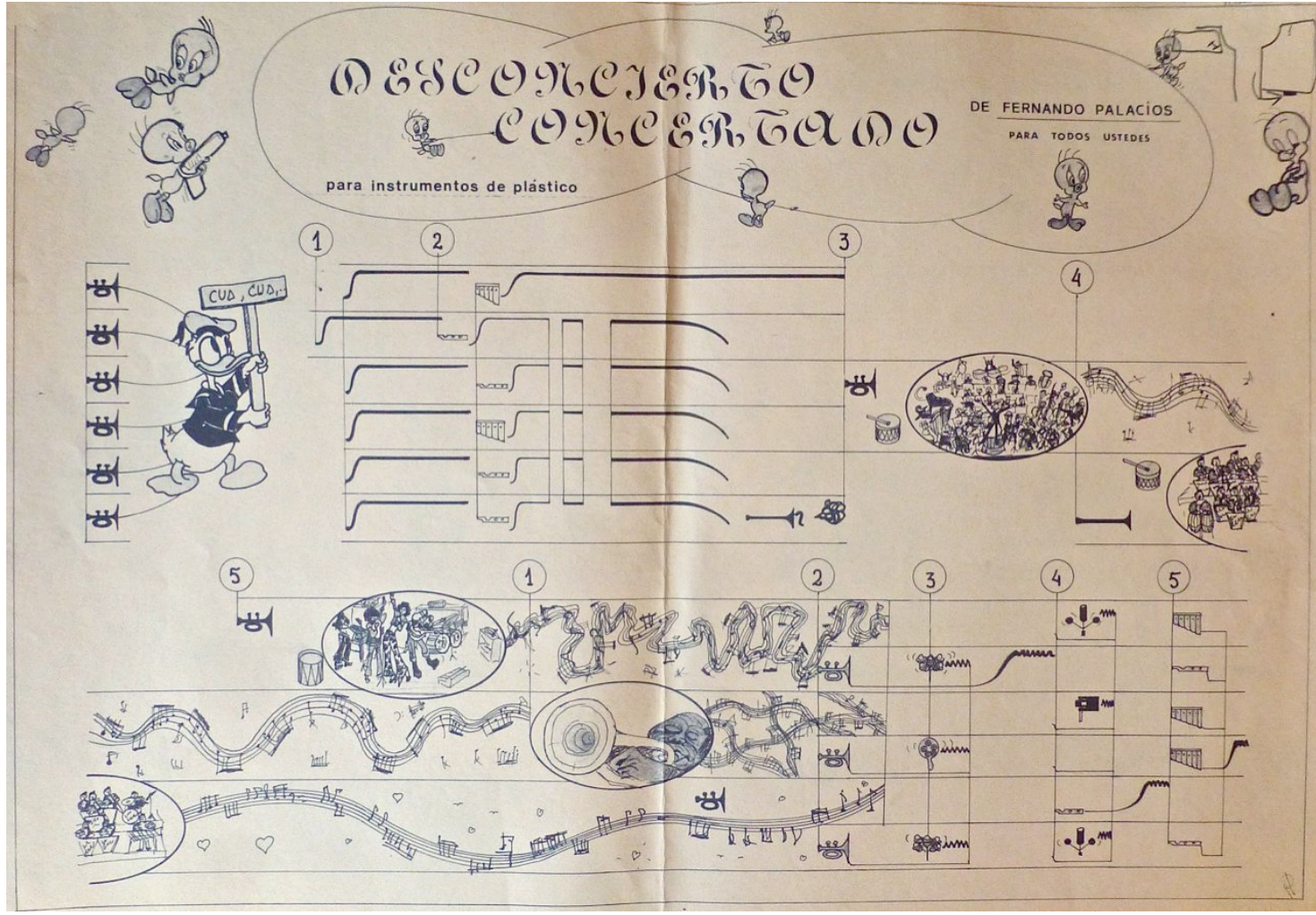

Fig.1 Desconcierto concertado (1980) de Fernando Palacios, partitura gráfica para instrumentos de plástico. @Fernando Palacios.

\section{Historia del desarrollo de las nuevas grafías.}

La Revolución Industrial llevó aparejada la aparición de nuevas creaciones artísticas que entendieron la música como medio de representar acústicamente el mundo que les rodeaba. Los futuristas italianos, con Luigi Russolo como máximo representante, iniciaron la creación de los más variados instrumentos musicales generadores de sonidos-ruidos de inspiración industrial, llamados intonarumori. La variación de la oscilación rotatoria de estos aparatos produciría una variación entre sonidos agudos y graves, pero sin los movimientos interválicos que hicieran necesaria la partitura tradicional.

Siguiendo esta evolución, los instrumentos musicales también sufrieron un enriquecimiento de sus posibilidades con la utilización de nuevas técnicas extendidas, llevando a los compositores a inventar signos que representaran estas funciones.

A partir de la década que corresponde a los años 1945-1955, surgen nuevos medios de producción sonora apoyados por el desarrollo de las nuevas tecnologías, es el nacimiento de la música concreta y de la música electrónica. Estas dos clases de nueva música no necesitarán la notación tradicional, aunque el sistema de partitura seguiría siendo válido en obras mixtas que combinaban recursos instrumentales con electroacústicos.

El primer compositor que daría el paso para representar simbólicamente una obra electrónica fue K. Stockhausen en su pieza Studio II (1954). Pero sería más adelante en la obra para percusión, piano y electrónica Kontakte (1959) donde trataría de establecer con mayor precisión esta relación entre sonidos electrónicos e instrumentos. El siguiente salto hacia delante de la notación vino dado por la aparición de la electrónica en vivo, que permitía reproducir el sonido y transformarlo en tiempo real, lo cual llevaría a los compositores a encontrar soluciones gráficas muy novedosas y atractivas.

La segunda vía para comprender la irrupción de la escritura grafista en la música centra su atención en el ámbito de la aleatoriedad y el experimentalismo. Tal como define el compositor Michael Nyman "a los compositores e intérpretes experimentales no les preocupaba tanto definir relaciones ya fijadas de antemano, sino que pretenden más perfilar situaciones en las que puedan darse sonidos, con ciertas normas composicionales, pero en las que se le podía pedir al intérprete que tomase decisiones casi a tiempo real fijando un número concreto de sonidos o eventos en un tiempo determinado" ${ }^{2}$. Del mismo modo también se le podía pedir al intérprete que emplease técnicas poco tradicionales para la interpretación o que utilizase todo tipo de utensilios como instrumentos.

\footnotetext{
${ }^{2}$ Nyman, M.: Música experimental. De John Cage en adelante. Girona: Documentia Universitari,2006, p.25.
} 
El compositor norteamericano John Cage fue pionero en aportar todas estas soluciones compositivas e introducirlas en la vanguardia europea junto a compañeros suyos como Morton Feldman y Earle Brown. Todos ellos compartían el interés en tomar como referente las artes plásticas y no tanto la tradición de la música occidental ${ }^{3}$.

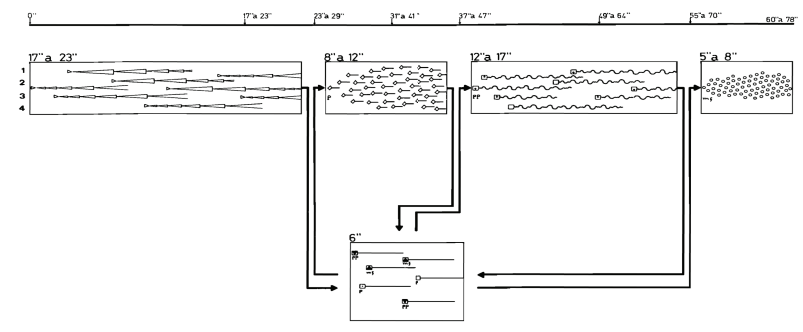

Fig. 2 -Juegos Gráfico Musicales III (1976) de Jesús Villa-Rojo, partitura gráfica para cuatro instrumentos de madera. (c) Editorial Alpuerto.

Los compositores de la escuela polaca como R. H. Ramati y K. Serocki y otros como Sylvano Bussotti y Salvatore Sciarrino aportarían partituras de gran riqueza visual y originalidad, con un gran valor plástico.

En España también encontramos composiciones gráficas en obras de Luis de Pablo, Josep María Mestres-Quadreny y Fernando Palacios. También Tomás Marco y los compositores del Grupo Glosa como Pablo Rivière, Alfredo Aracil, Francisco Guerrero y Tomás Garrido ofrecen casos puntuales de grafismos vinculados a la estética aleatoria.

Una labor importante en el desarrollo de las grafías musicales corresponde a Jesús- Villa Rojo, quien intenta aportar una sistematización de los gráficos y crea nuevos sistemas que representasen las nuevas técnicas extendidas de los instrumentos clásicos.

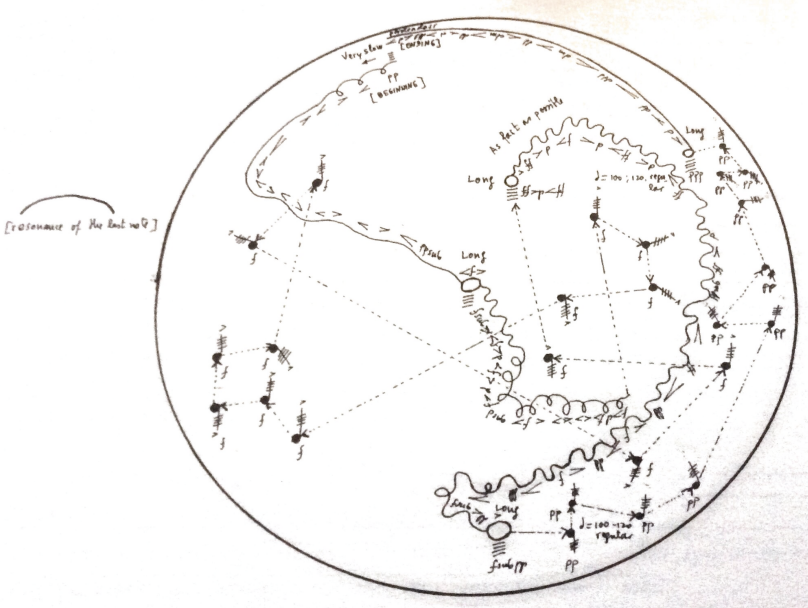

Fig. 3- Le prie-dieu sur la terrasse (1973) de Luis de Pablo, partitura gráfica @Edizioni Suivini Zerboni.

\footnotetext{
${ }^{3}$ Earle Brown lograría desarrollar una técnica que sería practicada después por muchos de los compositores serialistas europeos que estuvieron interesados en la aleatoriedad. Esta técnica estaba inspirada en los móviles de Alexander Calder y en ella el compositor propondrá una serie de "módulos" cuyo material musical interior está completamente determinado, estando el intérprete encargado de decidir su orden y combinación.
} 


\section{Las grafías de Skin's Traces.}

La obra Skin's Traces del compositor gijonés Juan José Eslava (1970) está compuesta para el instrumento frame-drum amplificado, la electrónica está controlada por el software Max-MSP y la partitura para el intérprete es un conjunto de grafías realizadas con trazos dibujados por pinceles japoneses (japanese brushes) siguiendo la intensidad de los gráficos el ejemplo de los sonogramas que se visualizan en el programa AudiSculpt. Como comenta el propio compositor su intención es la de "focalizar la composición sobre la energía interna del gesto lanza preguntas sobre la notación y la escritura. Skin's Traces usa un sistema de signos difusos analógicamente relacionados con la emoción de los gestos" ${ }^{4}$. Podemos comprobar como el compositor trabaja a partir de fuentes de diversa disciplina y procedencia, tanto del mundo oriental como del mundo occidental, siendo este un elemento que caracterizará la música de finales del siglo XX y principios del XXI.

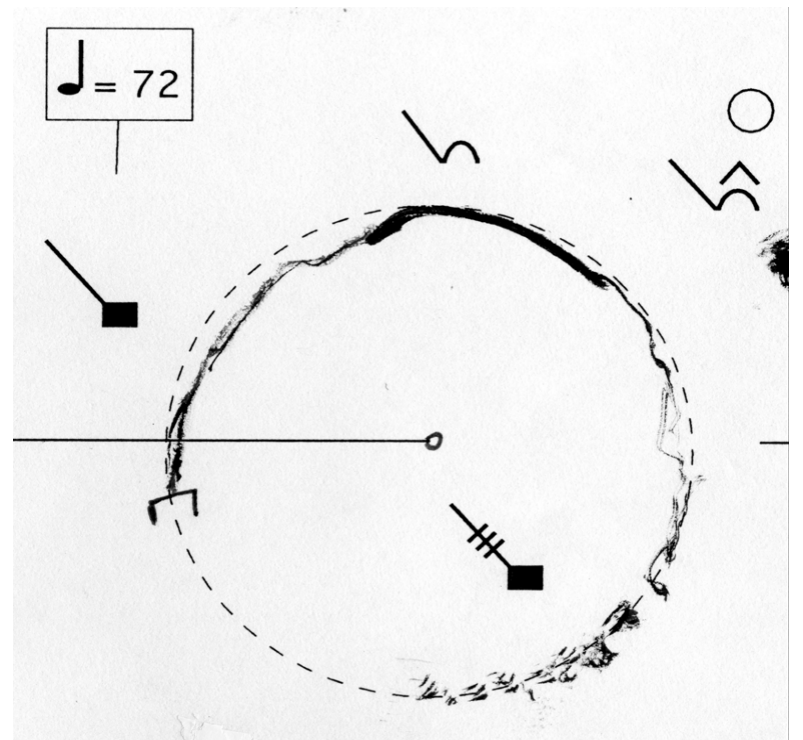

\section{4- Skin's Traces (2006) de Juan José Eslava, partitura gráfica. @ Juan José Eslava}

La partitura está dividida en varias partes, la sección que corresponde a las grafías, la línea rítmica que representa el ritmo resultante de las acciones percusivas y una última línea donde se indican los sonidos creados electrónicamente. Hay barras que dividen el compás, así como elementos rítmicos que son indicados con notación tradicional.

Para entender y descifrar mejor los trazos que componen la partitura de Skin's Traces tenemos que ir al origen de la caligrafía oriental y nos centraremos en el estilo cursiva loca de la caligrafía china.

En el estilo cursiva loca se utilizan manchas, gestos rápidos, espacios en blanco para representar elementos de la naturaleza y de los sentimientos. El pincel oriental utilizado para realizar estos trazos podía ser de muchos tipos: pelo de cerdo, liebre, cabra..., y tenía tres variedades: duro, suave y mezclado. Había tantas posibilidades en la elección del pincel como sensaciones se querían crear. En la interpretación de la obra, los trazos son realizados por el intérprete con las uñas, los dedos y las manos siguiendo las indicaciones de la partitura. El objetivo interpretativo será el de reflejar auditivamente todas las variedades de manchas y trazos que se reflejan en la partitura que han sido creadas por esta técnica de cursiva a través del pincel japonés. Los trazos son realizados en tinta negra y son gruesos, enérgicos y decididos, características que tendremos que reflejar en nuestra interpretación.

\section{Skin's Traces como ejemplo de música mixta.}

La evolución de las nuevas tecnologías aplicadas a la música electroacústica trajo consigo una nueva forma de relación entre instrumentos tradicionales y sonidos tratados electrónicamente. Como consecuencia de ello se han desarrollado nuevos programas para la visualización y el tratamiento de los fenómenos sonoros.

En Francia, dentro del Groupe de Recherches Musicales del INA de París, se ha desarrollado el Acousmographe que permite obtener la Transformada Rápida de Fourier (FFT) y luego dibujar, escribir, ubicar gráficos en planos superpuestos. De un modo análogo se ha creado en el IRCAM de París el programa AudioSculpt que sirve de referencia para crear las grafías de Skin's Traces.

AudioSculpt es una interfaz gráfica de representación de sonidos y de control de transformaciones de filtros y síntesis avanzada basada en el programa SVP (Super Vocoder de Phase) creada por el grupo de Análisis/Síntesis del IRCAM de París. AudioSculpt incorporará

\footnotetext{
${ }^{4}$ Eslava,J. J.: Skin's Traces, 2006. Disponible en: [Consulta 5 marzo 2017] http://www.eslava.eu/skinstraces.htm
} 
además la posibilidad de filtrar el sonido diseñando directamente sobre el sonograma, el tratamiento que se realice alterará los resultados del análisis y el sonido será obtenido por re-síntesis ${ }^{5}$.

El programa que utilizaremos para la interpretación de la obra será el Max-MSP. Es un entorno de programación gráfica creado especialmente para la generación y el procesamiento de sonido, imagen y video en tiempo real. Se trata de uno de los programas más difundidos, desarrollados y utilizados en música electrónica en vivo e instalaciones multimedia e interactivas ${ }^{6}$.

Max-MSP fue creado originalmente en el IRCAM en 1996 por Miller Puckette y David Zicarelli, y es desarrollado actualmente por Cycling 74.

Utilizaremos el programa Max-MSP en la obra Skin's Traces para lanzar los sonidos electrónicos y para configurar volúmenes y salidas de audio, además de permitirnos escuchar el click-track elaborado por el compositor que nos ayuda a seguir rítmicamente la parte electrónica y sincronizar con ella nuestra ejecución instrumental.

\section{El instrumento y la técnica instrumental empleada.}

El instrumento utilizado para la ejecución musical es el frame-drum (pandero). Se trata de uno de los instrumentos más antiguos y más extendidos a lo largo de todo el mundo. Muchos países y muchas culturas utilizan el frame-drum como instrumento rítmico. El término que utilizamos como frame-drum es el nombre genérico por el cual llamamos al tambor de un solo parche sujeto a un aro circular, pero dependiendo del país y de los accesorios que se le puedan añadir encontraremos otras denominaciones. Como ejemplo de esto tenemos el tar en el Norte de África, que es un pandero con sonajas y bordones, aunque también se le pueda llamar con este nombre al mismo instrumento que no tiene estos accesorios, pues en estas regiones no existe la denominación pandero o frame-drum.

El compositor Juan José Eslava nos propone para la obra "Un frame-drum circular (diámetro comprendido entre 45 y $60 \mathrm{~cm} .$, ideal $50 \mathrm{~cm}$.), piel fina natural (típicamente de cordero), si posible con rugosidades y pelos no excesivamente gastados, y sin ningún objeto adicional. De preferencia, pandero de origen iraní o indio".

La técnica empleada habitualmente para tocar estos instrumentos consiste en la utilización de los dedos, uñas y yemas en distintas zonas del parche para producir sonidos más graves o agudos con agarres que varían desde los llamados "Oriental", "Europeo" o "Tradicional", modificando la orientación del parche, dependiendo de la especificidad del instrumento y el contexto.

Para interpretar Skin's Traces necesitamos la utilización de las dos manos, por lo que el instrumento lo dispondremos estando sentados apoyado en nuestras piernas, en un agarre parecido al del "Lap style", en la que el intérprete está sentado y sostiene el pandero con la rodilla izquierda, con la mano izquierda apoyada en la parte superior. Es importante que instrumento se mueva lo menos posible para ejecutar mejor todos los distintos golpes y rasguños, por lo que nuestra posición corporal debe de estar fija, manteniendo la espalda recta.

Para producir y extraer la mayor riqueza tímbrica posible al instrumento el compositor demanda una variedad de acciones, golpes y rasguños, tanto percusivos como no percusivos, que debemos realizar adecuadamente creando una poética del gesto.

También será importante revelar los ritmos que se ilustran con notación tradicional en la rythmic line de la partitura. Estos ritmos serán extraídos para ser analizados y practicados técnicamente previamente por el intérprete.

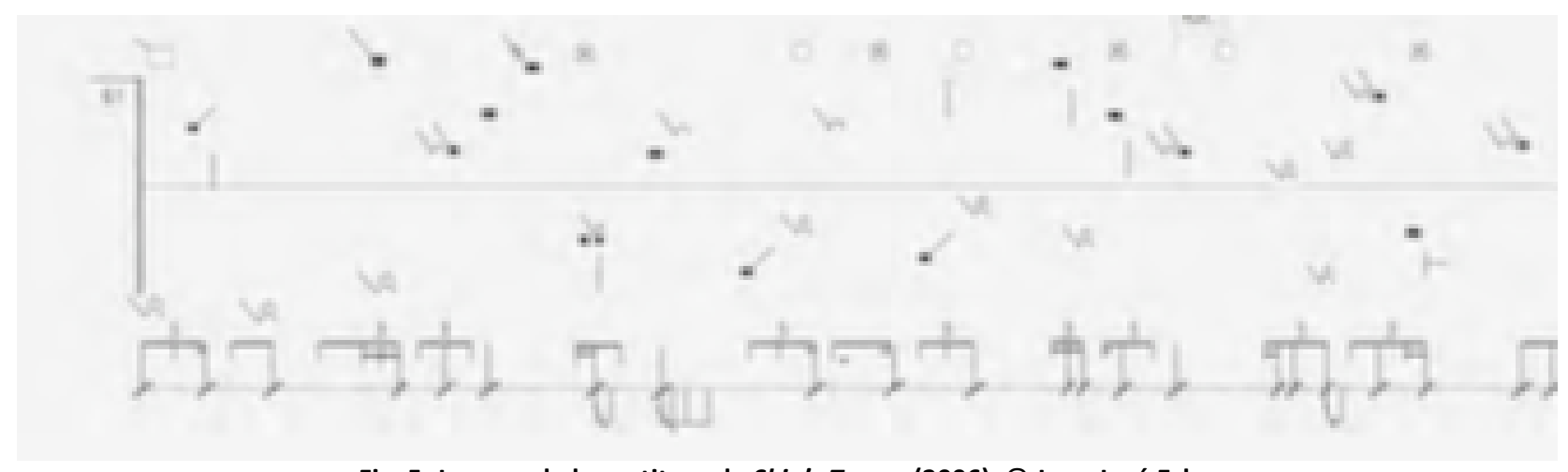

Fig. 5- Imagen de la partitura de Skin's Traces (2006). @ Juan José Eslava.

Para mejorar la práctica utilizaremos el programa Ableton Live que nos permitirá tanto bajar el tempo del click-track como el ensayo mediante repeticiones en bucle de distintos compases.

\footnotetext{
${ }^{5}$ BOGAARDS, N., RÖBEL, A. y RODET, X.: Sound Analysis and Processing with AudioSculpt 2. Proc. Int. Computer Music Conference (ICMC), 2004, pp. 2-5.

${ }^{6}$ Tutorial de Max MSP y Pure Data. [en línea], [sin fecha].[Consulta: 16 marzo 2017]. Disponible en: http://maxmsptutorial.blogspot.com.es/
} 


\section{CONCLUSIONES.}

La música para percusión del siglo XXI se define por su multiplicidad y por su globalidad de orígenes y contextos. En la obra Skin's Traces nos encontramos con una electrónica creada en un laboratorio musical europeo, con una escritura gráfica de tradición oriental y con un instrumento universal presente en la mayoría de culturas.

El compositor actual no es solo un organizador de sonidos, sino también un creador de ideas y suele exponer estas ideas tanto en ensayos como en reflexiones para después plasmarlas en la partitura. El intérprete-percusionista, como el calígrafo chino, debe ser artista creativo, filósofo y conocedor de todas estas fuentes para poder utilizar todas las herramientas y técnicas posibles. En esta comunicación, para su exposición pública, les mostraremos ejemplos de cómo la investigación repercute positivamente sobre la práctica, replanteando todo el proceso de estudio técnico. Incluiremos mi interpretación de la obra in situ como parte necesaria que confirmará las hipótesis planteadas.

\section{FUENTES REFERENCIALES.}

ARIZA, J.: Las imágenes del sonido: Una lectura plurisensorial en el arte del siglo XX. $2^{\text {a }}$ Edición. Cuenca: Ediciones de la Universidad de Castilla-La Mancha,2008.

BOGAARDS, N., RÖBEL, A. y RODET, X.Sound Analysis and Processing with AudioSculpt 2. Proc. Int. Computer Music Conference (ICMC), 2004,pp. 2-5.

COLLINS, N. Música electrónica en vivo. Quodlibet: revista de especialización musical, 2009, vol. 44, pp. 3-23.

DE PABLO, L. Le prie-dieu sur la terrasse. 1973. Edizioni Suvini Zerboni-Milano: s.n.

ESLAVA, J. J. Skin's Traces. 2006. S.I.: s.n.

ESLAVA, J. J. Skin's Traces [en línea],2006 [Consulta: 5 marzo 2017] Disponible en: http://www.eslava.eu/skinstraces.htm.

GARCÍA FERNÁNDEZ, I. D. El grafismo musical - Sinfonía Virtual. [en línea]. ,2017[Consulta: 5 marzo 2017]. Disponible en: http://www.sinfoniavirtual.com/revista/005/grafismo_musical_frontera_lenguajes_artisticos.php

GÓMEZ, J. La liberación del sonido. Las artes sonoras y su campo expandido. S.I.: Amarilys Quintero Ruiz, 2015

GONZÁLEZ, R.F.Influencias Zen de las pinturas monocromas orientales en obras de los artistas cubanos Tomás Sánchez, Leandro Soto y Rubén Fuentes. , DOI 10.4995/Thesis/10251/53631., 2015.

LIU, H.L. «Kuang Cao». El estilo cursiva loca de la caligrafía China y su relación con la pintura informalista. TDX (Tesis Doctorals en Xarxa), 2016

N. Scott Robinson-mundo de la música y percusión, tambores de marco, Riq, panderetas. [en línea], [sin fecha]. [Consulta: 16 marzo 2017]. Disponible en: http://www.nscottrobinson.com/framedrums.php.

NYMAN, M. Música experimental. De John Cage en adelante. Girona: Documentia Universitaria, 2006

VILLA ROJO, J. Notación y grafía musical en el siglo XX. S.I.: Iberautor, 2003.

Tutorial de Max MSP y Pure Data. [en línea], [sin fecha]. [Consulta: 16 marzo 2017]. Disponible en: http://maxmsptutorial.blogspot.com.es/ 